\title{
ELECTRON SPIN RESONANCE SPECTROSCOPY OF
}

COMMERCIAL HUMIC ACIDS IN COMPARISON WITH

NATURAL HUMIC ACIDS EXTRACTED FROM SOIL AND SOME

NATURALLY DECOMPOSED AGRICULTURE WASTES

\author{
M.H. Badr and Asmaa Al-Amir \\ Faculty of Science (Girls), Al-Azhar University
}

\begin{abstract}
Concentration of free radicals, g-values, and line widths of the ESR spectra were determined for three commercial humic acids used for agriculture in Egypt and compared with three natural humic acids extracted from soil and two decomposed agricultural wastes including olive mill solid residual and rice straw - cattle manure mixture. The natural regional soil humic acid shows lower free electron contents. The calculated free radical contents of the commercial humic acids were found to be abnormally higher than not only the studied natural humic acids but also than the cited literature humic acids originated from different sources. All the g-values indicate semiquinonic radical moieties associated with an aromatic network or a semiquinone radical unit conjugated to aromatic rings of different type. Higher g- values recorded for the studied humic acids indicate oxygen-centered radicals. The relations govern the line-width and gvalue, the line-width and the shape of the esr signal, spin concentration and \%0, spin concentration and $\% \mathrm{H}$, spin concentration and absorbance at $465 \mathrm{~nm}$., spin concentration and atomic $\mathrm{C} / \mathrm{H}$ ratios are more significant in case of natural humic acids extracted from soil and the two composts but not in case of commercial humic acid. This indicates that the two humic acids classes are basically different in their structures.
\end{abstract}

\section{INTRODUCTION}

Soil organic matter (SOM) is a mixture of simple and complex organic compounds including macromolecular structures (Humus). Humus usually classified as humic acid (HA), fulvic acid (FA) and humin (HU). They are basically classified in relation to their solubility in alkali and acid (Sérgio et al., 2003). Humic substances contain very stable semiquinone free radicals and provide free radicals to plant cells. These free radical play an important role in the majority of chemical reactions between organic, organomineral and mineral compounds in soils due to their large store of energy and high activity. (Evgeny et al., 2005). The freeradical content can be used as indicator of the humic acids reactivity toward several chemical and biochemical reactions. 
They function as electron donors and assist in exerting positive effects on seed germination, root initiation and plant growth in general. Quinones are responsible for the formation of reactive oxygen species in HAs, which are useful for wound healing and have fungicidal/bactericidal properties. Phenols and carboxylic acids deprotonate in neutral and alkaline media and are responsible for various other functions, such as the antioxidant and anti-inflammatory properties of HAs. In particular, the presence of phenolic groups in HAs provides antioxidant properties due to their free radical scavenging capacity (De melo et al., 2016). Free radicals contain one or more unpaired electrons, are highly reactive, short lived, and capable of participating in many different reactions. It is believed that the semi quinone free radicals in humic acids are stabilized by aromatic structures. They are associated with humification degree of humic acid (Rifalde and Schintzer, 1972). The greater the humification (low H:C ratios) the darker the color of the humus the higher free radical content.(Robert, 2008). Considerable interest are given to the study of free radicals in humic acids in soil and other natural sources (i.e. coal, peat, compost, sediment, fresh and marine waters) and synthetic sources (Senesi et al., 1987).

Electron spin resonance (ESR) spectroscopy can detect free radical compounds, determine its concentration and, sometimes, their origin. At present, electron paramagnetic resonance spectroscopy has become a common method, along with nuclear magnetic resonance spectroscopy for studying the humification and stabilization of humic substances in soils, peats, and other sediments (Willson and Weber, 1977; Scott et al., 1998; Dai et al., 2001; Ejarque and Abakumov, 2001).

On other hand humic acids have potential to be used as an effective conversation and management tool for sustainability of the soil (Gümü and Seker, 2015). Commercial organic or organomineral fertilizers usually contain between 15 and $85 \%$ of humic substances, extracted from lignite, leonardite, or peat by oxidation. These materials are sources with a very high content of humic substances (Lamar et al., 2014).

According to Lodhi et al. (2013), studies revealed that humates available in the market vary widely and therefore some sort of quality monitoring is required.

The aim of this work was to apply electron spin resonance spectroscopy (ESR ) to analyze some commercial humic acids applied in agriculture in Egypt and compare their characteristics with humic acids extracted from Egyptian soil and from two decomposed agricultural wastes include, solid waste of olive oil mill and rice straw cattle manure mixture.

\section{MATERIAL AND METHODS}

Commercial humic acids samples: Three commercial humic acids ( HA1, HA2 and HA3) were obtained from three Egyptian 
sellers. The data recorded on the three acids were shown in Table (1).

Soil sampling: The soil sample was taken from the $\mathrm{Ah}(0-15 \mathrm{~cm})$ horizon of soil cultivated with apricot trees in Shobra shehappe area-province of Kaliobeya, at the northern of Cairo, Egypt. The soil sample was air dried, and the plant residue was removed as possible before humic acids, (HAsoil) extraction.
Decomposed rice straw - cattle manure mixture: Fresh cattle manure was mixed by stirring with dry and grounded rice straw. After three days the bad odor disappears. The past was made in form of strips and spread in air and sunlight.

The dried past was grounded. The powder was used for extraction of humic acid, (HArcm).

Table (1): The commercial acids recorded data

\begin{tabular}{|l|c|l|}
\hline HA & Content & source \\
\hline HA1 & 98\%Humic acid & India \\
\hline HA2 & $\begin{array}{c}\text { 95\% potassium humate appearance crystal } \\
\text { granules of size } 0.5-1.5 m m, \text { water solubility } \\
12 \% \text { max,pH }=9-10 .\end{array}$ & China \\
\hline HA3 & HA68\%,Fulvic 18\% Potassium10\% & Canada \\
\hline
\end{tabular}

\section{Decomposed olive cake solid waste:}

The solid olive oil mill waste was derived from Alkttan factory in Cairo. The waste was stored without supporting with any plant residues or additives under irregular atmospheric conditions. The extraction and purification of humic acids, (HAov), was conducted after stored about 2 years.

\section{Extraction and Purification of humic}

acids: Extraction and purification of humic acids was carried out according to international humic substances society (HISS) (Swift 1996), with slight modifications (Badr et a l., 2005)

Humic acids analysis:-

Moisture and ash Contents. Doublicate sample were dried at $105^{\circ} \mathrm{C}$ for 24 hours to determine moisture contents (Sim Siong et al., 2007), then ignited in a muffle furnace at
${ }^{750} 0^{\circ} \mathrm{C}$ for $8 \mathrm{hrs}$. to determine the ash content (Ghabbour and Davies, 2000).

Elemental Analysis**1 ${ }^{1}$ C, H, N and, S percentages were determined for all humic acids on the Elemental vairo EL 111 Analyzer. The oxygen content was estimated from the difference $(0 \%=100 \%-\% \mathrm{C}-$ $\% \mathbf{H}-\% \mathbf{N}-\mathrm{S} \%)$.

E4/E6 ratio: Humate solutions were prepared by dissolving $0.05 \mathrm{~g}$ of purified humic acids in $25 \mathrm{ml}$ of $0.5 \mathrm{~N} \mathrm{NaOH}$ solution in absence of air. The pH was adjusted to 7 by adding 0.1N HCl. A blank was set up under the same condition according to Theng et al. (1967). Based on the determined absorbance values at wavelength

*Microanalytical Center, Faculty of Science, Cairo university Egypt, Cairo

**The National Center of Radiation Research and Technology, Nasr City, Cairo 
465nm and $665 \mathrm{~nm}$ on Perkin Elmer, Precisely Lambada 45,UV/VIS Spectrometer, the ratio of the two absorbance (E4/E6 ratios) were calculated. Electron spin resonance (ESR) measurements** were made on low-ash, finely ground humic acid samples that had been dried over a desiccant. The study of organic free radicals was accomplished by EPR, through the Bruker- EMX spectrometer with rectangular cavity of ER 4102, operating in band $X$ (approximately 9.5GHz) and wavelength is about $3 \mathrm{~cm}$.).The weight was determined by transferring the powder humic acid sample to Quartz tubes have inner diameter about $3 \mathrm{~mm}$. All measurement occurs under room temperature conditions. The electromagnetic radiation can be regarded as coupled electric field (E) and magnetic field $(H)$, where the two fields are perpendicular to each other and the direction of propagation, and they oscillate by the same frequency $v$ within the range from 1 to 100 Giga Hertz as the modulation frequency is $100 \mathrm{kHz}$.

The ESR parameters describe the organic free radical and calculated from the resultant ESR spectrum include:

(a) The concentration of unpaired electrons (free radicals) expressed in spins/g, estimated by comparing the area of the ESR signal of the sample with that of a standard char containing a known number of paramagnetic centers, on the assumption that the area, calculated by double integration or, more commonly, by multiplying the height and square of the width. According to. Gohn, (1986). The equation used for Spin calculation was as follows:

$$
\mathrm{N}=\mathrm{K} \frac{H_{o} \times(\Delta H)^{2} \times(P . H / w t \cdot)}{\mathrm{Ge} \times \mathrm{Hm} \times \sqrt{P}}
$$

Where:N: no. of spins, $H_{0}$ : magnetic resonance, $\Delta \mathrm{H}$ : peak width, $\mathrm{Ge}$ : gain. $\mathrm{Hm}$ : modulation amplitude, $P$ : power, $K$ : EPR constant $=1013$ spins

(b) g-value or the spectroscopic splitting factor, was measured by comparing the values of the magnetic field at which resonance occurs for the sample and for a standard of known g-value, generally $\mathrm{N}, \mathrm{N}$ diphenylpycrylhydrazyl (DPPH); the results were read on the spectrometer which calculated according to the

following relations:

$$
\boldsymbol{g}_{\text {sple }}=2.0036 \times \frac{\mathbf{H}_{\text {std }}}{\mathbf{H}_{\text {sple }}} \times \frac{\mathbf{V}_{\text {sple }}}{\mathbf{V}_{\text {std }}}
$$

Where $H_{\text {std }}$ and $H_{\text {sple }}$ are the instrument magnetic fields with the standard and $V_{\text {sple }}$ are the instrument frequencies of the standard and sample.

(c) The width of the resonance line, and sample, and $\quad \mathbf{V}_{\text {std }}$ measured in Gauss as the peak-to-peak separation of the first- derivative ESR signal according to Saleh et al. (1982). 
The ESR spectrometer setting parameters were as it follows: Center Field ve-Power2012 Mw Time Constant 81920ms, Sweep Time 201972s, ModFrequency100.00 KHz, Mod-Amplitude5.00 G Receiver Gain7.96 E+03, Number of Scan 1. g// g. $\perp$

\section{RESULTS AND DISCUSSION}

The ESR spectra of the investigated humic acids are shown in Fig. (1) and (2). The shapes were similar to those generally observed for humic acids from different sources (Rifalde and Schintzer, 1972;
3460.410 G, Sweep width 200.00 MicrowaveFrequency, $\quad 9.712703$ GHZ, Microwa Chukov et al., 2017). All spectra consisted of a single spectra devoid of hyperfine splitting, which may be ascribed to the high number of super imposed resonances at slightly differing field values, all contributing to the signal (Kubát, 2012) or to presence of more than one kind of radical center (Anderson et al., 1974). indicated that the free radicals in humic acid are extremely of complex structure.

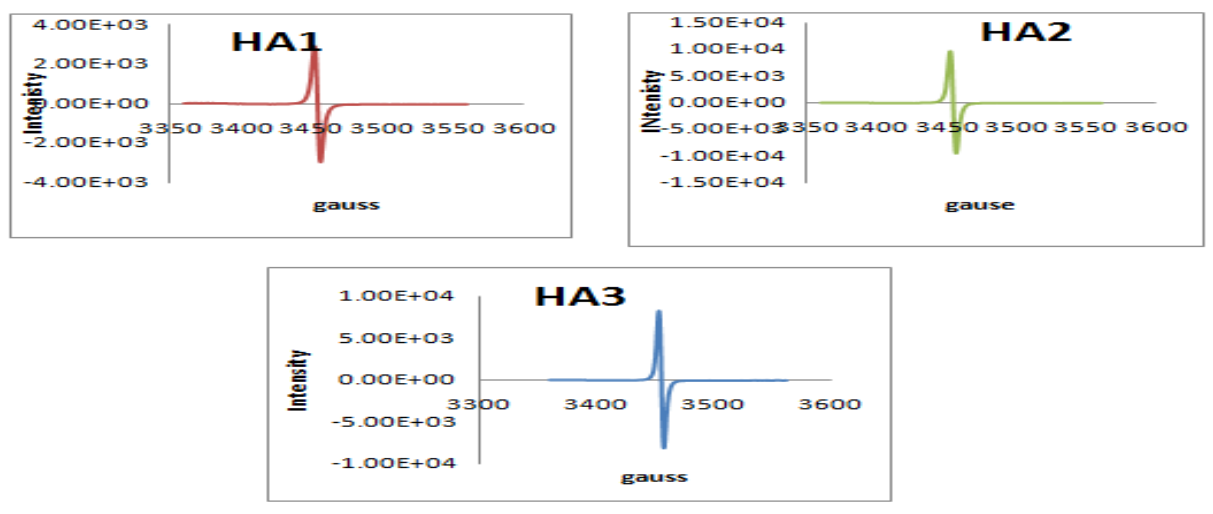

Fig. (1): ESR spectra of the three commercial humic acids HA1, HA2, and HA3
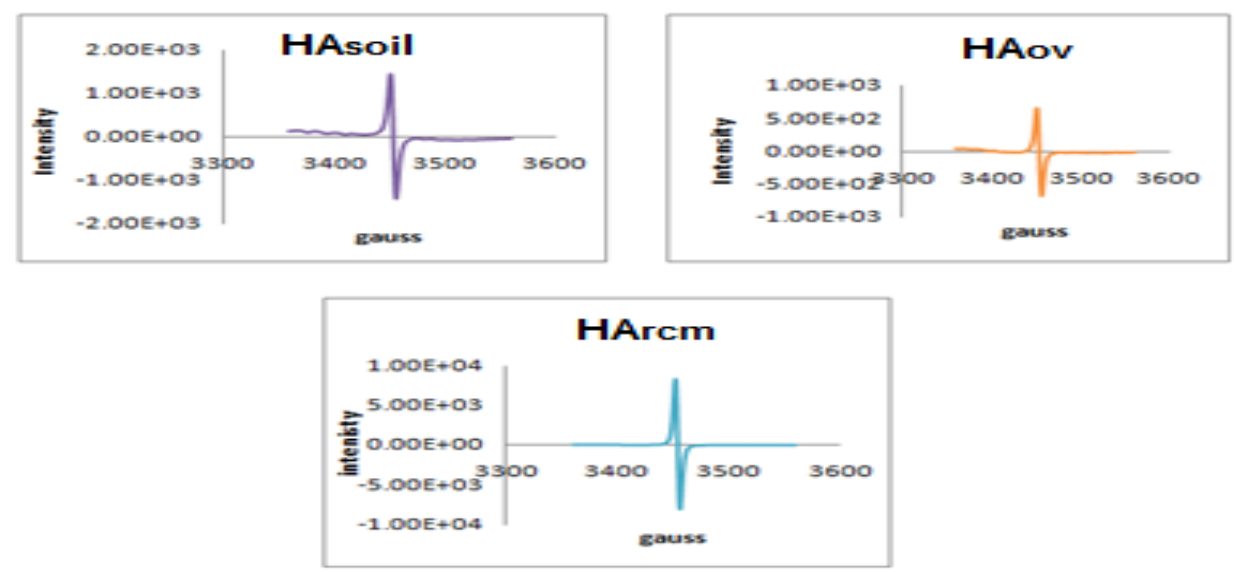

Fig. (2): ESR spectrs of the soil, decomposed olive solid waste and decomposed rice straw- cattle manure humic acids: HAsoil, HAov, and HArcm of line widths 4.07, 5.07 and $7.05 \mathrm{G}$ respectively. 
Free radical contents: The calculated free radical concentrations of the studied humic acid in comparison with humic acids from different sources are shown in Table (2). Free radical concentrations of Egyptian soil humic acids in comparison with humic acids extracted from soil at different geographic region are shown in Table (3). The calculated free radical contents of commercial humic acids (HA2 and HA3) were found to be higher than not only the studied natural humic acids but also than the cited literature humic acids values. According to (Baranclkova et al., 1997) this result indicates the higher poly condensed and aromatic nature of the commercial humic acids, with respect to the regional studied humic acids. In recent point of view, the low degree of organic matter humification is confirmed by the increased content of free radicals as determined by electron paramagnetic resonance, which indicates a low bio- thermodynamic stability of organic matter (Chukov et al., 2017).

According to the data given in Table (3), it is observed that each soil humic acids is characterized by its own contents of free radicals which is related to its nature.

Table (2): The free radical contents of the studied humic acid in comparison with humic acids smples from different sources

\begin{tabular}{|c|c|c|c|c|c|}
\hline $\begin{array}{c}\text { Studied } \\
\text { HA }\end{array}$ & $\begin{array}{l}\text { Spin/gm } \\
\times 10^{17}\end{array}$ & $\begin{array}{c}{ }^{1} \text { Peat HA } \\
\mathrm{X} 10^{17}\end{array}$ & $\begin{array}{l}{ }^{2} \text { SoilHA } \\
\text { X } 10{ }^{17}\end{array}$ & $\begin{array}{c}{ }^{3} \text { Fungal } \\
\text { HAX10 } 17\end{array}$ & $\begin{array}{l}{ }^{4} \text { Coal } \\
\times 10^{17}\end{array}$ \\
\hline HA1 & 6.40 & \multirow{2}{*}{0.9795} & \multirow{2}{*}{3.0} & \multirow{2}{*}{5.67} & \multirow{2}{*}{0.8} \\
\hline HA2 & 14.63 & & & & \\
\hline HA3 & 12.88 & 2.8002 & 5.2 & 6.41 & 7.8 \\
\hline HAov & 01.38 & 0.0589 & 2.6 & 2.88 & 4.1 \\
\hline HAr- & 02.72 & 0.1753 & & 0.62 & 6.7 \\
\hline$\frac{\text { cm }}{\text { HA soil }}$ & 02.15 & 1.7086 & 4.0 & 1.36 & \\
\hline
\end{tabular}

. (1Kjavins and Sire Pdf),( 2Anderson et al. 1974 ),( 3Senesi et al., 1987),(4Deborah. et al., 2002), 
Table (3): Free radical concentration of Egyptian soil humic acids (HAsoil) in comparison with humic acids extracted from soil at different geographic region

\begin{tabular}{|r|l|c|}
\hline $\begin{array}{c}\text { Soil } \\
\text { No. }\end{array}$ & \multicolumn{1}{|c|}{ Sources of humic acid } & $\begin{array}{r}\text { Free radical } \\
\text { concentration } \\
\text { Spin X10 } 0^{17} \mathrm{~g}^{-1}\end{array}$ \\
\hline 1 & Gray forest soil(Chiba,Japan)* & 4.7 \\
2 & Paddy field soil (Chiba,Japan)* $^{*}$ & 1.0 \\
3 & Farm soil(Chiba,Japan)* $^{*}$ & 2.8 \\
4 & Wisconsinpodzol** $^{* *}$ & 8.0 \\
5 & Muck soil** $^{* *}$ & 3.0 \\
6 & California podzol** & 2.0 \\
7 & English podzol** & 14.0 \\
8 & Arizona brown-forest soil** & 8.0 \\
9 & IHSS standard soil** & 12.9 \\
10 & Egyptian soil & 2.15 \\
\hline
\end{tabular}

*(Ghabbour and Davies, 2002), **(Frederick, 1970),IHSS:

international humic substances societ.

Also, it is noted that the Egyptian soil humic acid was in the third rank after California podzol and Paddy field soil, Japan. Generally the relatively low free electron content in soil humic acids may attributed to the decomposition of organic matter by the higher temperature.

The g- factor provides information about the chemical nature of the species that contains the unpaired electron, (Marcilene et al., 2010). The g-factor value of unbound electron equal to 2.0023 as reported by Natalya et al. (2016). According to Evgeny et al. (2005) the ESR spectral line with $g=$ 2.003 suggesting presence of free radicals in structure of humic acids . When the $\mathrm{g}$ factor is close to that of a free electron this points to existence of strongly delocalized molecular orbits. Senesi et al. (1987) reported that the g-values range from 2.0040 to $\mathbf{2 . 0 0 4 6}$ are consistent with semiquinonic radical moieties associated with an aromatic network.

Schnitzer and Skinner (1969) have drawn a similar conclusion for soil humic acids, in which the most likely possibilities are semiquinone radicals associated with a condensed ring system or a mixture of two or more different types of free radicals. Retcofsky et al. (1968) have reported a gradual decrease in $g$ value with coal rank (from 2.00418 to 2.00270) and considered that g-value of semiquinone radicals decreases as the size of the condensed ring system increases.

Also the g-values of ESR spectra can be used to assess whether a radical is carboncentered or oxygen-centered: whether the unpaired electron is located on a carbon or oxygen atom. Carbon centered radicals have 
g-values that are close to the free electron $g$ value 2.0023. Carbon centered radicals with an adjacent oxygen atom have higher gvalues in the range of $\mathbf{2 . 0 0 3 - 2 . 0 0 4}$, while for oxygen-centered radicals have g-values that are > 2.0048, (Catherine et al., 2009).

According to the above review, and according to the g-values obtained and showed in table (4) in comparison with humic acids from different sources, the free radical contents of commercial humic acids ( HA1, HA2 and HA3) and regional humic acids (HAov, HArcm and HAsoil) are semiquinone radicals associated with a condensed ring system or a mixture of two or more different types of free radicals. The higher values recorded for the g-values indicate small molecular size and lor oxygen centered

free radicals.

Table (4): The g-factors the studied humic acids in comparison with humic acids from different sources.

\begin{tabular}{|c|r|r|r|r|r|}
\hline \multirow{2}{*}{ Hmic acid } & & \multicolumn{4}{|c|}{ g- value } \\
\cline { 5 - 6 } & g- value & ${ }^{1}$ Peat & ${ }^{2}$ Soil & ${ }^{3}$ Fungal & ${ }^{4}$ Coal \\
& & HA & HA & HA & HA \\
\hline HA1 & 2.00876 & 2.006 & 2.0031 & 2.0041 & 2.0056 \\
\hline HA2 & 2.00877 & 2.006 & 2.0030 & 2.0040 & 2.0058 \\
\hline HA3 & 2.00881 & 2.005 & 2.0028 & 2.0043 & 2.0056 \\
\cline { 1 - 1 } HAov & 2.00916 & 2.0065 & 2.0030 & 2.0041 & 2.0055 \\
\hline HArcm & 2.00954 & 2.005 & 2.0029 & 2.0046 & \\
\cline { 1 - 2 } HAsoil & 2.00893 & 2.006 & 2.0030 & & \\
\hline
\end{tabular}

. ( ${ }^{1}$ Kjavins and Sire Pdf $),\left({ }^{2}\right.$ Anderson et al. 1974$),\left({ }^{3}\right.$ Senesi et al., 1987), $\left({ }^{4}\right.$ Deborah. et al., 2002). As the commercial humic acids prepared by oxidation of a coal source, the higher of values observed in case of commercial acids suggests that the free electrons in these acids are more shifted toward the oxygen atoms which in agreement with (Abakumov et al., 2015).

The line width value is related with the time that the excited electron spends to return to the environment of the absorbed energy (relaxation time) and also with the interaction of the organic free radical with the environment. The more condensed the molecules, the smaller the line width (William et al., 2008).
The calculated line width values are shown in Table (5 )in comparison with humic acids from different sources. The group of commercial humic acids HA1, HA2, HA3 and soil humic acid HAsoil presented small values of line width, and in a general agreement with the literature soil humic acids . These small values are associated with abnormal high concentration of organic free radicals in case of commercial humic acid. The largest value for line width was observed for the humic acids of the compost group (HArcm and HAov) which indicate that these were less humified. in accordance with (Cunha et al., 2009) . 
According to Anderson et al. (1974), it was observed that: (a) the greater the line-width, the greater the g-value, and b) as the linewidth increased, the line-shape changed from asymmetric to Lorentzian to Gaussian (Fig 3)

Table (5): the line width of the studied humic acids in comparison with humic acids from different sources

\begin{tabular}{|c|c|c|c|c|c|c|c|}
\hline \multirow{2}{*}{ Humic acids } & \multicolumn{2}{|c|}{ ESR characteristics of studied humic acids } & \multicolumn{4}{c|}{ Line width } \\
\cline { 2 - 5 } & Spin/ g x10 ${ }^{17}$ & G-facto & Line width & ${ }^{1}$ Peat & ${ }^{2}$ soil ${ }^{3}$ FPHA* ${ }^{*}{ }^{4}$ coal \\
\hline H A1 & $\mathbf{6 . 3 9 9 6 2}$ & 2.00876 & 4.45 & 1.6 & 4.3 & 5.8 & 5.0 \\
\hline HA2 & 14.6297 & 2.00877 & 4.08 & 1.5 & 4.1 & 5.5 & 5.6 \\
\hline HA3 & 12.8772 & 2.00881 & 4.08 & 1.4 & 2.9 & 4.8 & 5.2 \\
\hline HAov & 1.38431 & 2.00916 & 5.07 & 1.4 & 4.1 & 5.1 & 4.1 \\
\hline HArcm & 2.71457 & 2.00954 & 7.05 & 1.5 & 3.3 & 6.6 & - \\
\hline HAsoil & 2.15361 & 2.00893 & 4.07 & 1.5 & 4.1 & - & - \\
\hline
\end{tabular}

. $\left({ }^{1}\right.$ Kjavins and Sire Pdf $),\left({ }^{2}\right.$ Anderson et al. 1974$),\left({ }^{3}\right.$ Senesi et al., 1987), $\left({ }^{4}\right.$ Deborah. et al., 2002$)$. *fungal type humic acids

Table ( 6 ) shows elemental analysis, concentration Vs. \%O shows direct absorbance at $465 \mathrm{~nm}$, against spin concentration of the studied humicacids. Fig (4) shows the plot of $\% \mathrm{H}$ and $\% \mathrm{O}$ in soil and decompsed humic acids vs.spin concentrations. Fig (5) shows plot of \% $\mathrm{H}$ and $\% \mathrm{O}$ vs.spin concentrations in commercial humic acids. For soil and decomposed wast humic acids, a plot of spin concentration Vs. \%H shows an inverse relationship between the two parameters which was statistically significant at $\mathrm{R} 2=0.65$; the plot of spin

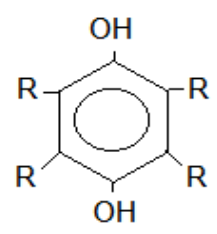

According to Fig ( 2) and the data showed in Table (5 ) the last phenomena observed only in case of soil and decomposed wast humic acids which indicate the similarity and related structure. proportionality which was statistically significant at $\mathbf{R}^{2}=0.58$. generally, According to ( Reffaldi and Schnitzer 1972) the statistically significant negative correlations between spin concentration and $\% \mathrm{H}$ and the positive correlation between spin concentration and \%O in case of soil and decomposed wast humic acids support a mechanism of free radical formation which involves the oxidative removal of $\mathrm{H}$ from OH by action such as the following:<smiles>[R]c1c([R])c(O)c([R])c([R])c1O</smiles>

The latter results are not given by commercial humic acids as shown in fig (5). Other statistically significant correlations $(R 2=0.97)$ were found to exist between spin concentration 
and absorbance at $465 \mathrm{~nm}$ for soil and decomposed waste humic acids Fig (6). The statistically significant correlations between spin concentration and absorbance at $465 \mathbf{~ n m}$ suggest that the free radicals content is related to the dark color humic substances.

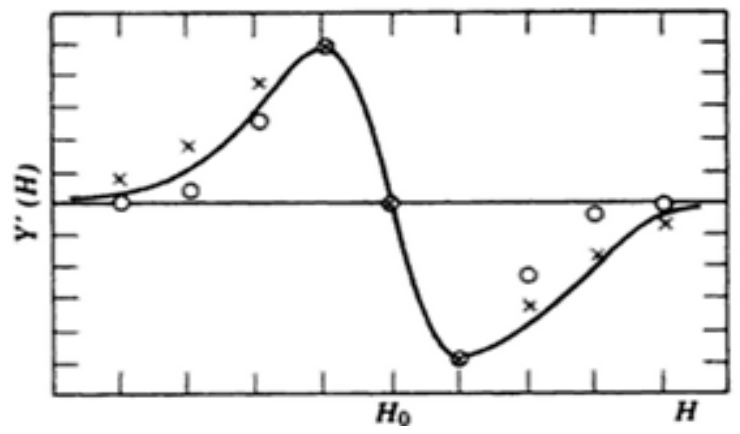

Fig (3): An asymmetric experimental spectrum matched to $(\mathrm{X})$ lorentzian and (O)Gaussian shapes with the same amplitude.

Table (6): The elemental analysis, absorbance at $465 \mathrm{~nm}$, against

Spin concentrations of the studied humic acids

\begin{tabular}{|c|c|c|c|c|c|}
\hline S.sample & H\% & O\% & C/H & A465 & Spin concx10 $^{18}$ \\
\hline HA1 & 2.36 & 33.97 & 0.46 & 0.293 & 63.9962 \\
\hline HA2 & 2.25 & 32.11 & 0.47 & 0.309 & 146.297 \\
\hline HA3 & 2.79 & 29.65 & 0.50 & 0.341 & 128.772 \\
\hline HAov & 9.62 & 20.54 & 1.71 & 0.035 & 13.8431 \\
\hline HArcm & 6.26 & 23.03 & 1.33 & 0.257 & 27.1457 \\
\hline HAsoil & 5.37 & 36.47 & 1.21 & 0.196 & 21.5361 \\
\hline
\end{tabular}



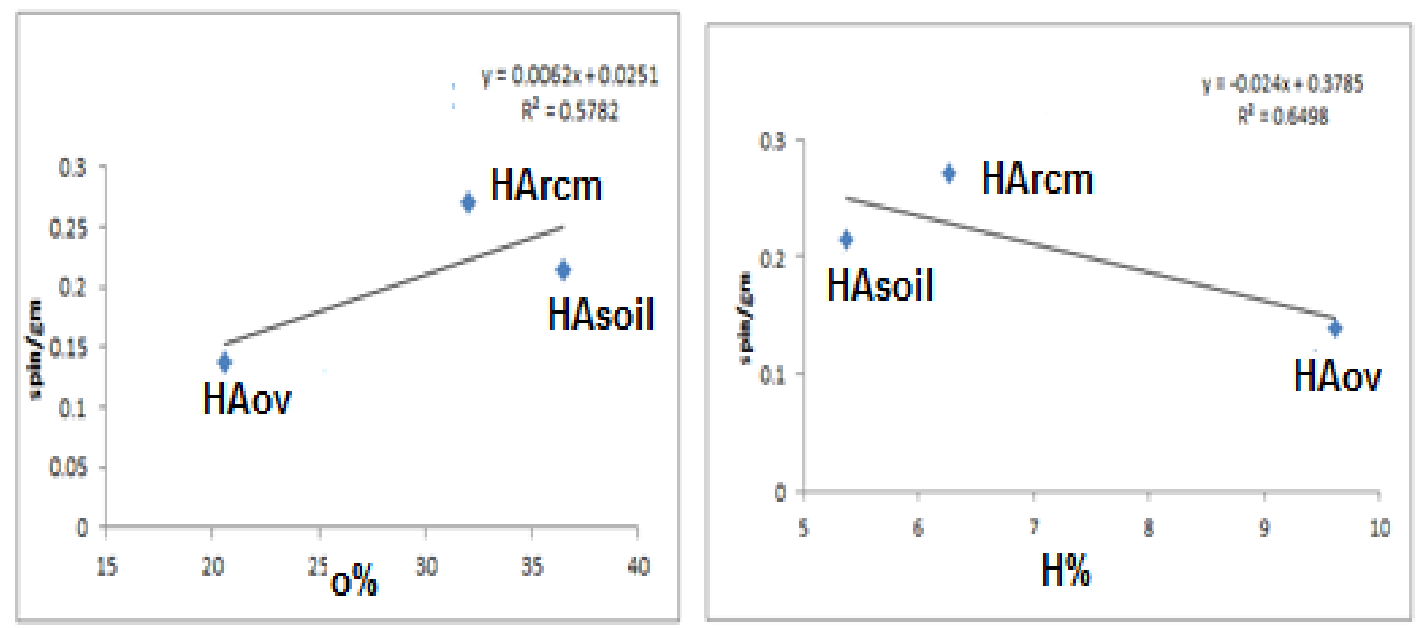

Fig (4): Plot of \% $\mathrm{O}$ and \% $\mathrm{H}$ vs.spin concentrations in soil and decomposed waste humic acids
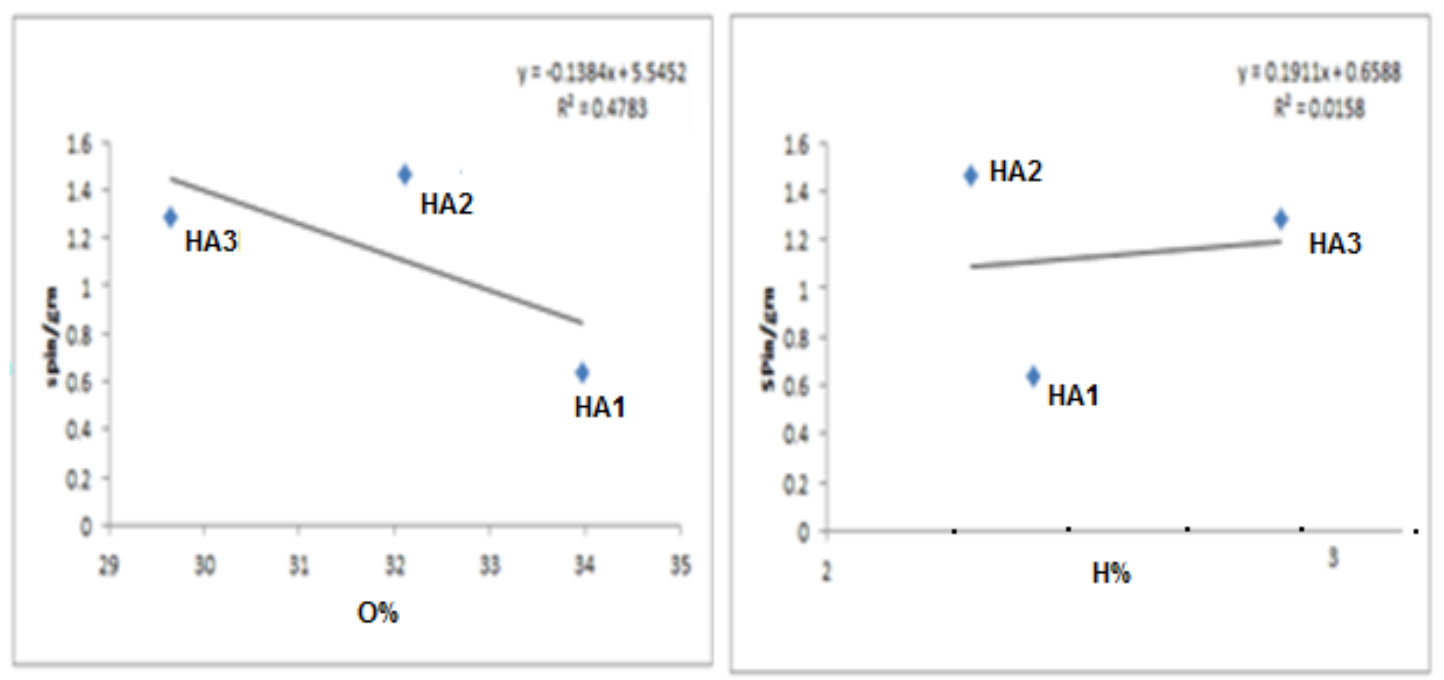

Fig (5): Plot of \% $\mathrm{O}$ and $\% \mathrm{H}$ in commercial humic acids vs.spin concentrations

Generally, this result also not observed in case of commercial acids. Observations connecting free radicals content of humic material with color have also been made by Reffaldi and schnitzer (1972). The corelation between spin concentration and atomic $\mathrm{C} / \mathrm{H}$ ratios Fig (7) indicates as the degree of condensation (aromaticity) or the molecular complexity of the humic acid increase, the free radical content also increases. This is more significant in case of natural humic acids extracted from soil and decomposed waste than commercial humic acids. Soil and decomposed waste humic acids have $\mathrm{C} / \mathrm{H}$ ratio generally coincident with the range 0.779 -1.594 of natural humic acids( Reffaldi and Schnitzer, 1972) while commercial humic acids small values outside the natural range. 

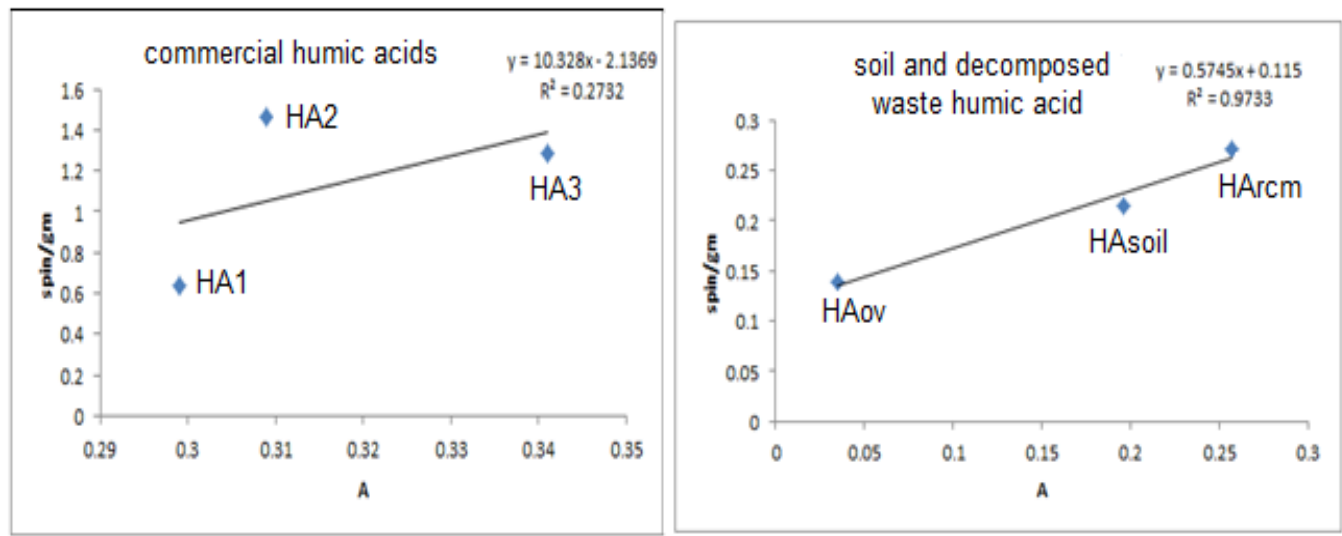

Fig (6): Plot of absorbances at 465nm of aquauos solution (pH 7). vs spin concentrations of commercial, soil, decopomsed olive solid residual, and decopomsed rice straw- cattle manure mixture humic acids .
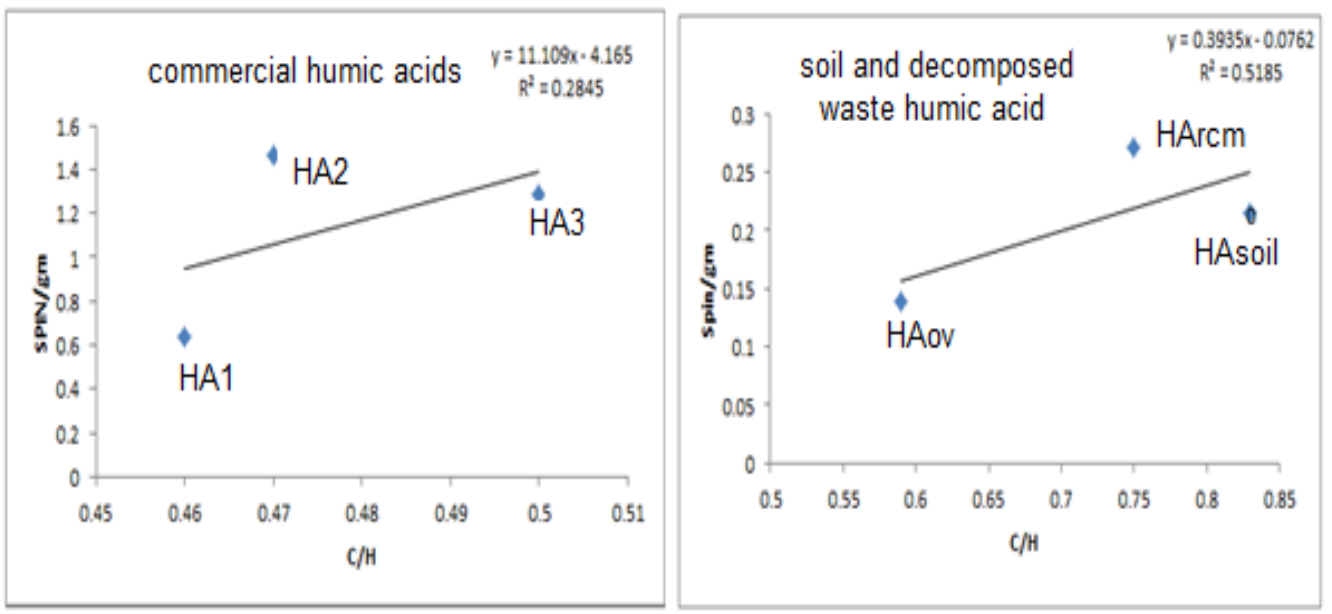

Fig (7): Plot of C/ H vs.spin concentrations in commercial, soil,decoposed olive solid residual and decopomsed rice straw- cattle manure mixture humic acids

\section{CONCLUSION}

The investigated commercial humic acids contain high content of organic free radicals comparing with the Egyptian soil and decomposed waste humic acids. The latter gave results consistent with the cited observed characteristics of natural acids while commercial humic acids were not. Commercial humic acids gave $\mathrm{Cl} H$ atomic ratios outside the natural humic acids range .The results indicate that the two classes are of basically different structure and low quality of commercial humic acids .

\section{REFERENCES}

Abakumov E. Lodygin, and V. Tomashunas (2015): ${ }^{13} \mathrm{C}$ NMR and ESR characterization of humic substances 
isolated from soils of two siberian arctic islands, International Journal of Ecology 7 pages, http://dx.doi.org/10.1155/2015/3905

Anderson WD, DB Russell, RJ ST Arnaud, and EA Paul (1974): A comparison of humic fractions of chernozemic and luvisolic soils by elemental analyses, UV and ESR spectroscopy. Can. J. Soil Sci. vol. 54(1) pp.447.

Badr MH, Abdel Gawad LI and Shabon MH (2005): Physiological effect of natural humic acid during pregnancy on fetuses and maternal alterations induced by irradiation in rats. Isotop \& RAD. RES.,.37(3): 749.

b Rancikova G, Senesi N, Brunetti G (1997): Chemical and spectroscopic characterization of humic acids isolated from different Slovak soil types. Geoderma, 78(3-4): 251.

Catherine $\mathbf{P}$ Koshland, Linwei Tian, Junko Yano, Vittal K. Yachandra, Ignatius TS Yu, SC Lee, and Donald Lucas (2009): Carbon-centered free radicals in particulate matter emissions from wood and coal combustion, Energy Fuels, 21; 23(5): 2523.

Chukov SN, Ejarque E, Abakumov EV (2017): Characterization of humic acids from tundrasoilsof northern Western Siberria by electron paramahgnetic resonance spectroscopy Eurasian Soil Science,.50 (1): 30 .

Cunha T.J.F, E.H Novotny, BE Madari, L. Martin-Neto, MO de O Rezende,
LP Canelas and V de M Benites (2009): Spectroscopy characterization of humic acids isolated from Amazonian Dark Earth Soils. WI Woods et al. (eds.), Amazonian Dark Earths: Wim S ombroek's Vision, 363 Chapter 20

Dai XY, CL Ping, R Candler, L Haumaier, and W Zech (2001): Characterization of soil organic matter fractions of tundra soils in Arctic Alaska by carbon-13 nuclear magnetic resonance spectroscopy, Soil Sci. Soc. Am. J. 65(1); 87.

De Melo BA, Motti FL and Santana MH (2016): Humic acids: structural properties and multiple functionalities for novel technological developments, Mater Sci Eng C Mater Boil, pp.962.

Deborah P Dick, Antonio S. Mangrich, Sonia MC Menezes and Betania F Pereira ( 2002): Chemical and spectroscopical characterization of humic acids from two South Brazilian Coals of different Ranks, J. Braz. Chem. Soc.,.13(2) Print version ISSN 010350530n-line version ISSN 1678-4790

Ejarque E.and E. Abakumov (2016): Stability and biodegradability of organic matter from Arctic soils of Western Siberia: insights from 13C-NMR spectroscopy and elemental analysis," Solid Earth, 7: 165.

Evgeny D. Lodygin1, Vasily A. Beznosikov1, Serafim N. Chukov (2005): Paramagnetic properties of humic substances extracted from Albeluvisols of North-Eastern 
European Russia, Latvijas Universitātes Raksti. (692), pp. 49.

Frederick M. Swain (1970): Non-marine organic geochemistry, Cambridge University Press, pp 72, Faculty of Geography and Earth sciences, University of Latvia, 19 Raina Blvd, LV586, Riga.

Ghabbour, E.A.and G. Davies (2000): Humic substances versatile components of plants, soil and water. Royal Socity of Chemstry.UK, pp.112.

Gohn A. (1986): ESR and Elementary particle applications, John, Wiely. New Yourk Canelas, L.P and V. de M Benites (2009): Spectroscopy characterization of humic acids isolated from Amazonian Dark Earth Soils. WI Woods et al. (eds.), Amazonian Dark Earths: Wim Sombroek's Vision, 363 Chapter 20.

Gümü, I. S and Seker C. (2015): Influence of humic acid applications on modulus of rupture, aggregate stability, electrical conductivity, carbon and nitrogen content of a crusting problem soil. Solid Earth vol. 6, p.1231.

Kjavins $M$ and J.sire ,Variations of humic acid properties within peat profiles. Faculty of Geography and Earth Sciences, University of Latvia, 19 Raina Blvd,LV 1586, Riga, Latvi

Kubát J. (2012): Humus, its Structure and role in Agriculture and Environment ,Elsevier p.13.

Lamar RT, Olk DC, Mayhew L, Bloom PR; (2014): A new standardized method for quantification of humic and fulvic acids in humic ores and commercial products. J AOAC Int vol. 97, p.721.

Lodhi, Asma; Tahir, Shermeen; Iqbal, Zafar; Mahmood, Ansar; Akhtar, Muhammad; Mahmood, Qureshi, Tariq; Yaqub, Muhammad (2013): Characterization of commercial humic acid samples and their impact on growth of fungi and plants, Soil \& Environment, 32 (1): 63.

Marcilene F. Barriquello, Sergio da Costa Saab, Nelson Consolin Filhoc and Ladislau Martin-Neto (2010): Electron paramagnetic resonance characterization of a humic acid-type polymer model. J. Braz. Chem. Soc., 21 (12): 2302.

Natalya Chukhareva, Mikhail Sartakov, and Tatiana Korotchenko (2016): Alteration in composition of heated peat humic acids elemental and functional MATEC Web of Conferences matecconf/. 858501004-CCT

Retcofsky, HL, Stard, JM, and Friedel, RA (1968): Electron spin resonance in American coals. Anal. Chem.40:1699.

Rifaldi, R; Schintzer M (1972): Electron spin resonsce spectrometry of humic substabces, Soil SCI. Soc. Am.J.; 36: 301.

Robert E. Pettit on line, 2008, pdf, organic matter, humus, humate, humic acid, fulvic acid and humin: their importance in soil fertility and plant health, Emeritus Associate Professor Texas A\&M University.http://www.humates.com/pdf 
Saleh FY, L. J. Theriot, S. K.Amani, and Inyoung Kim (1982): Electron Spin resonance of fulvic and humic acids from the Suwannee River. Government Printing office U.S. Geological Survey Water- supply Paper, PP.67.

Schnitzer,M., and Skinner,S.I.M. (1969): Free radicals in soil humic compounds . Soil sci .vol.108, pp.383.

Scott DT, DM Mc Knikt, EL Blunt-Harris, SE Kolesar, and DR Lovley, (1998): Quinone moieties act as election acceptors in the reduction of humic sub-stances by humic reducing microorganisms, Environ. Sci. Technol., 32: 2894.

Senesi N., TM Miano, and JP Martin (1987): Elemental, functional infrared and free radical characterization of humic acidtype fungal polymers (melanins) Biol Fertil Soils, (5):120.

Sérgio C. Saab,Ladislau Martin-Neto(2003): Studies of semiquinone free radicals by ESR in the whole soil, HA, FA and humin substances, J. Braz. Chem. Soc., .14,pp1.

$\begin{array}{rccr}\text { SimSiong } & \text { Fong; } & \text { Lau } & \text { Seng; } \\ \text { NorrafidahBtMajri; } & \text { HaslindaBt } & \text { Mat }\end{array}$

(2007): A comparative evaluation on the oxidative approaches for extraction of humic acids from low rank coal of Mukah, Sarawak. J. Braz. Chem. Soc., .18(1):34-40.

Swift RS (1996): In Organic matter characterization, Vol. 3, Sparks D. et al (Madison WI,).Ch. 35,pp. 1018.

Theng GKB, Wake RJ, Posner MM (1967): The humic acids extracted by various reagents from a soil ii. infra-red, visible, and ultra-violet absorption spectra $J$. of Soil Science, 18: 349.

Willson SA and JH Weber (1977): Electron spin resonance analysis of semiquinone free radicals of aquatic and soil fulvic and humic acids," Anal. Lett, 10(1): 75.

William I. Woods, Wenceslau G. Teixeira, Johannes Lehmann, Christoph Steiner, Antoinette MGA. WinklerPrins, Lilian Rebellato (2008): Amazonian Dark Earths: Wim Sombroek's Vision ,Springer Science \& Business Media,pp.370 


\section{إستخدام طيف الرنتن المغرلي الإلكتزونى في الاقارنة بين أهماض الهيوميك

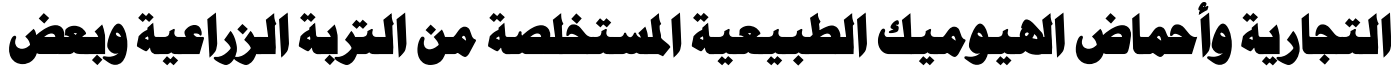 \\ المغلفات الزراعية المتمبالة}

هبدة حسين ابراهيم واسماء الامير

كلية العلوم (بنات) جامعة الازهر

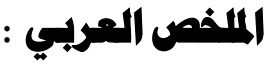

تم تحديد تركيز الجذور الحرة (الثوارد الحرة ) وقيم معامل ال g وعرض خط طيف الرنين الاكترني المغزلي لثلاثة احماض هيوميك تجارية من السوق المصري مقارنة مع ثلاثة أحماض طبيعية مستخرجة من التربة الزراعية

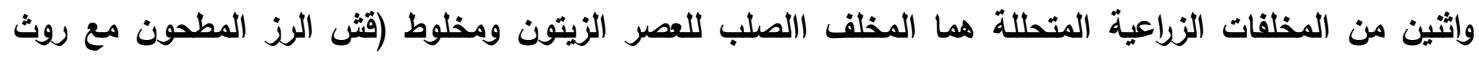

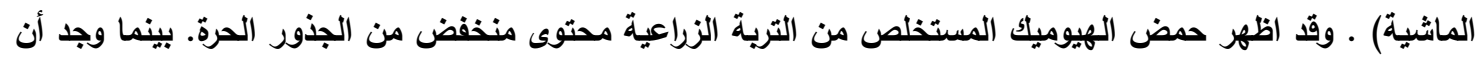

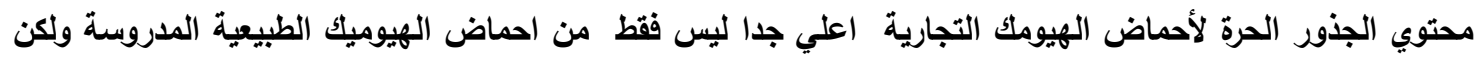
أيضا من قيم الجذور الحرة المنشورة لأحماض هيوميك مستخلصة من مصادر مختلفة. تثبر جميع قيم g إلى ان الجذور الحرة موجودة على شقوق semiquinon مرتبطة بشبكة عطرية أو وحدة semiquinone المدروسة ان الجذور متمركزة في ذرات أكسجين.

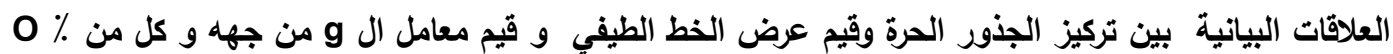

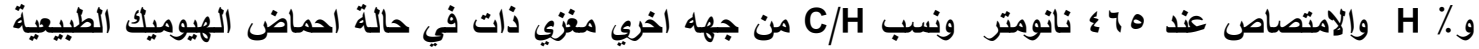

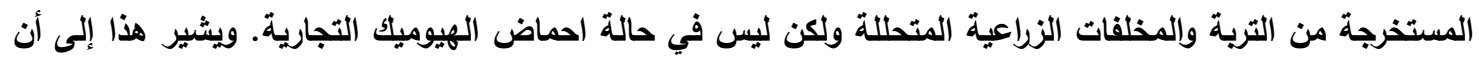
فئتي الأحماض الدبالية تختلفان بشكل أساسي في بنائهما. 